\title{
Patients' perspectives on allocation of publicly funded in vitro fertilization in Ontario: a qualitative study
}

\author{
Angela Assal MD MHSc, Nipa Chauhan MHSc, Eyun-Jung Shin MSc, Kerry Bowman PhD, \\ Claire Jones MD
}

\section{Abstract}

Background: The aim of this study was to determine consumers' perspectives on fair allocation of publicly funded in vitro fertilization (IVF) in the recently implemented Ontario Fertility Program (OFP). The research questions were as follows: 1) What factors do those who require IVF think are important to consider when distributing funded IVF? and 2) What are the barriers to accessing publicly funded IVF?

Methods: We approached this qualitative study with a social constructivist interpretative framework with grounded theory methodology. Data were obtained via focus group. We recruited participants eligible for the OFP from a tertiary care fertility clinic. Two researchers conducted all interviews, independently reviewed the transcriptions and analyzed the data for open coding, followed by axial coding and then selective coding to determine themes.

Results: A total of 13 participants (10 women and 3 men with an average age of 36.4 [range 28-40.7] yr) partook in 4 focus groups. The average duration of infertility was 1.9 (range $0.4-3$ ) years. Three important domains were identified. First, the procedure of distributing funds should be done in a transparent and consistent manner. Second, everyone should have a fair and equal chance to accessing the funds. Participants suggested a combination of first-come, first-served and a scoring system as a method to distribute funds. Lack of communication, associated costs and stress of experiencing infertility were cited as barriers to accessing publicly funded IVF.

Interpretation: Ensuring equal and fair access to funds should be prioritized, and information about the process and distribution method to obtain OFP funding should be clearly provided to patients. Transparency, standardization and better communication should be implemented to uphold procedural justice for patients and reduce emotional stress. The findings may be considered by policy-makers to improve the current OFP and when developing similar programs.

\footnotetext{
[ n Ontario, $1 \%-2 \%$ of live births are achieved with assisted reproductive technology. ${ }^{1}$ The Ontario Ministry of Health and Long-Term Care introduced the Ontario Fertility Program (OFP) on Dec. 21, 2015. ${ }^{2}$ Through the program, each Ontario woman under the age of 43 is eligible for 1 publicly funded in vitro fertilization (IVF) cycle in her lifetime. ${ }^{2}$ The OFP is limited to 5000 annual IVF cycles, distributed among fertility clinics based on historical demand. After the program was implemented, there was substantial demand, and wait-lists of up to 1.5 years were reported. ${ }^{3}$ Clinics were required to develop their own strategies for resource allocation. No principles of prioritization were suggested by the Ministry of Health and Long-Term Care. In addition to the cost of medications (about $\$ 5000$ per IVF cycle), private IVF costs about $\$ 10000-\$ 15000$, and, thus, finances can be a barrier to access. ${ }^{4}$ The cost of medications is not covered by the OFP. Geographic barriers also exist, as OFP-funded clinics are heavily concentrated in the Greater Toronto Area. ${ }^{5}$
}

A 2016 survey of fertility clinics in Ontario showed that 38\% of clinics distributed funded IVF on a first-come, first-served basis, $10 \%$ used a lottery system, and $52 \%$ used multiple factors (e.g., patient age, duration of infertility). ${ }^{6}$ No clinics consulted patients when developing their allocation methods. ${ }^{6}$ Gotz and colleagues $^{7}$ surveyed 271 patients about their opinions regarding the OFP and its implementation. Most respondents $(84.5 \%)$ thought that all clinics should use the same allocation method. Although the majority of respondents (70.8\%) thought the method of distribution should be based on a scoring system rather than a lottery $(1.5 \%)$ or first-come, first-served $(18.5 \%)$,

\section{Competing interests: None declared.}

This article has been peer reviewed.

Correspondence to: Nipa Chauhan, nipachauhan@gmail.com

CMAJ Open 2019. DOI:10.9778/cmajo.20180182 
there was disagreement about which factors to prioritize in the scoring system. We conducted a qualitative study to obtain a deeper understanding of patients' perspectives. The study objectives were to determine the following: 1) What factors do those who require IVF think are important to consider when distributing funded IVF? and 2) What barriers to accessing publicly funded IVF exist?

\section{Methods}

\section{Design}

We approached this study with a social constructivist interpretive framework, based on the expectation that participants would describe multiple ethically justifiable views. We chose grounded theory methods to generate a theory that is grounded from the data resulting from participants' shared experiences. ${ }^{8,9}$ Grounded theory aids in the systematic collection and analysis of data, and construction of a theoretical model. ${ }^{8}$

\section{Participant recruitment and study setting}

We used purposeful sampling to capture patients waiting for OFP-funded IVF and who eventually received OFP-funded IVF. ${ }^{8}$ English-speaking Ontario residents capable of consent and eligible for the OFP, including partners, were included in the study. Women seeking IVF who were aged 43 years or more were excluded, as they are ineligible for OFP-funded IVF. Participants were recruited by means of poster advertisements in the waiting room at our institution's fertility clinic. The current method of allocating OFP-funded IVF at this clinic is first-come, first-served. All participants provided written consent and completed a demographic questionnaire (Appendix 1, available at www.cmajopen.ca/content/7/2/ E385/suppl/DC1) before participation.

\section{Data collection}

We planned to conduct at least 4 focus groups with 2-5 participants each, with further focus groups intended until data saturation was reached. We chose focus groups to allow for interparticipant communication and deliberation. We determined the size of the focus groups based on a balance of study feasibility and ensuring adequate data would be collected. Participants were allocated to groups according to whether they had received a funded IVF cycle or were still waiting. All focus groups were in-person and lasted 1 hour. They were facilitated by 2 research team members (A.A. and N.C). The discussions were audio-recorded and transcribed verbatim. We developed a topic guide based on available literature ${ }^{4,6,10}$ and expert discussion (Appendix 2, available at www. cmajopen.ca/content/7/2/E385/suppl/DC1). Information available on the Ontario Ministry of Health and Long-Term Care website was used as an introduction to ensure that participants understood the OFP structure. ${ }^{4}$ We used issues identified from previous studies of patient perspectives on publicly funded $\mathrm{IVF}^{6,10}$ to generate a list of issues that were then reviewed by authors and experts (colleagues at the Mount Sinai Fertility Clinic) to develop the topic questions. The for- mat of the guide was based on published qualitative methodology. ${ }^{9}$ After the focus group, participants were asked to write a rank list of 5 factors that should be prioritized for allocation of OFP-funded IVF cycles.

\section{Data analysis}

The focus group and rank list transcriptions were analyzed independently by 2 members of the research team (A.A. and N.C.) using thematic analysis. Data analysis began with manual review of the transcription for open coding, followed by axial coding and then selective coding to determine themes; no software was used. ${ }^{6}$ After data analysis, A.A. and N.C. met to compare coding. Discrepancies were discussed and resolved with 2 other team members (K.B. and C.J.). A.A. then reviewed the original transcriptions again to ensure that the final themes captured the essence of the data. Expertise in resource allocation ethics from A.A., N.C. and K.B. provided insight into the relevant themes implicit within participants' perspectives. Data saturation was considered achieved when consistent themes emerged with minimal new categories. The themes were then interpreted to answer the study questions. All members of the research team agreed on final themes and interpretations. Demographic data from the questionnaire were analyzed with descriptive statistics.

\section{Ethics approval}

Approval for the research was granted by the Mount Sinai Hospital Research Ethics Board.

\section{Results}

We conducted 4 focus groups with a total of 13 participants, 10 women and 3 men with an average age of 36.4 (range 28-40.7) years. The average duration of infertility was 1.9 (range $0.4-3$ ) years (Table 1).

A summary of the themes developed from participants' discussion and the rank list exercise are presented in Table 2.

With respect to our first study question (factors that are important to consider when distributing funded IVF), we found 3 domains: addressing the procedural aspect of fund distribution, the substantive content regarding factors to consider when allocating funds, and balancing these factors. The philosophical themes of justice discussed below (procedural, substantive and distributive) are defined in Appendix 3 (available at www.cmajopen.ca/content/7/2/E385/suppl/DC1.

\section{Procedural justice}

\section{Transparency from clinics}

Participants felt that there is a current lack of transparency about the process of funding allocation and when dealing with the fertility clinics in general:

I wasn't made aware of any sort of transparent process, I was just told I'm on a wait-list with no contact information or where I am on the wait-list. Is it a lottery wait-list? Is it a time-based waitlist? I ... didn't know it's the clinic [itself] that [is] doing it. (Focus group 3; participant 2) 
Table 1: Patient demographic characteristics

\begin{tabular}{|c|c|}
\hline Characteristic & $\begin{array}{c}\text { No. }(\%) \text { of } \\
\text { patients* } \\
n=13\end{array}$ \\
\hline \multicolumn{2}{|l|}{ Gender } \\
\hline Female & $10(77)$ \\
\hline Male & $3(23)$ \\
\hline Age, yr, mean (range) & $36.4(28-40.7)$ \\
\hline \multicolumn{2}{|l|}{ Region of residence } \\
\hline Toronto & $6(46)$ \\
\hline Greater Toronto Area & $6(46)$ \\
\hline No answer & $1(8)$ \\
\hline \multicolumn{2}{|l|}{ Relationship status } \\
\hline Married & $12(92)$ \\
\hline Partnered & $1(8)$ \\
\hline \multicolumn{2}{|l|}{ Ethnicity } \\
\hline White & $7(54)$ \\
\hline Other† & $5(38)$ \\
\hline No answer & $1(8)$ \\
\hline \multicolumn{2}{|l|}{ Annual household income, \$ } \\
\hline $25000-34999$ & $1(8)$ \\
\hline $50000-74999$ & $2(15)$ \\
\hline $75000-99999$ & $2(15)$ \\
\hline 100 000-149999 & $2(15)$ \\
\hline 150 000-199999 & $4(31)$ \\
\hline$\geq 200000$ & $2(15)$ \\
\hline \multicolumn{2}{|l|}{ Funded IVF status } \\
\hline Received IVF & $6(46)$ \\
\hline Waiting for IVF & $7(54)$ \\
\hline Duration of infertility, yr, mean (range) & $1.9(0.4-3)$ \\
\hline \multicolumn{2}{|l|}{ Duration of infertility, $\mathrm{yr}$} \\
\hline$<1$ & $2(15)$ \\
\hline 1 to $<2$ & $3(23)$ \\
\hline 2 to $<3$ & $4(31)$ \\
\hline$\geq 3$ & $4(31)$ \\
\hline \multicolumn{2}{|l|}{ Reason for requiring IVF } \\
\hline Polycystic ovarian syndrome & $2(15)$ \\
\hline Same-sex couple & $1(8)$ \\
\hline Post chemotherapy & $2(15)$ \\
\hline Low sperm count & $1(8)$ \\
\hline Chromosomal anomalies & $1(8)$ \\
\hline Reduced ovarian reserve & $1(8)$ \\
\hline Medical issue & $1(8)$ \\
\hline Unexplained/unknown & $4(31)$ \\
\hline \multicolumn{2}{|l|}{ Previous fertility treatment(s) } \\
\hline None & $2(15)$ \\
\hline Timed intercourse & $7(54)$ \\
\hline Intrauterine insemination & $7(54)$ \\
\hline IVF & $4(31)$ \\
\hline \multicolumn{2}{|l|}{ No. of previous pregnancies } \\
\hline 0 & $6(46)$ \\
\hline 1 & $4(31)$ \\
\hline 2 & $1(8)$ \\
\hline 3 & $1(8)$ \\
\hline 4 & $1(8)$ \\
\hline \multicolumn{2}{|l|}{ No. of children at home } \\
\hline 0 & $9(69)$ \\
\hline 1 & $4(31)$ \\
\hline
\end{tabular}

Participants cited issues regarding a scarcity of data about clinic success rates, allocation procedures and the number of available funded cycles at each clinic.

\section{Consistency among clinics}

Most participants assumed that OFP funding allocation was a centralized process or at least standardized among clinics, and argued that inconsistency is contradictory to our Canadian health care system. Participants identified that, without a centralized, standardized process, they would be motivated to "shop around" fertility clinics to increase their chances at obtaining publicly funded IVF.

There has to be [the] same criteria. It kind of made me mad, to be honest, that now I have to shop around? To see which clinic I would have better options with? (Focus group 2; participant 1)

\section{Gatekeeping of funding wait-list}

Participants described inconsistencies between clinics regarding the time of registration on the clinic's IVF wait-list. They expressed that entering the wait-list should be standardized and transparent; for example, registration should be done at the first visit or be based on objective clinical criteria.

\section{Substantive and distributive justice}

\section{Provide a fair chance and equal access to in vitro fertilization}

There was contention over the prioritization of equal access versus optimizing the outcome of successful live births. Most participants believed that the goal of the program should be to provide people a fair chance at having a child:

I think when you define success, to the ministry it's live births. I know that's the end goal, but success ... as a society ... is the access. That is, giving everybody a chance. Even for me, if I had multiple cycles and it didn't work ... the end result wasn't live birth, but ... emotionally ... I would feel like I gave it all my all. ... And that would have [given] me peace of mind no matter the age. (Focus group 3; participant 2)

Participants felt that older women should receive priority so they could obtain funding before exceeding the age limit, even though the probability of a live birth declines with increasing age. ${ }^{11}$ This was with the caveat that a physician would recommend IVF only if there was a "reasonable" chance of pregnancy.

Some participants felt that outcome should be primarily considered from a cost-effectiveness perspective. They suggested giving priority to younger women, recognizing that they have a higher chance of a live birth and are less likely to have complications than older women. Some participants also thought that older women would be more likely to afford privately funded IVF.

\section{Methods of distribution of funds by clinics}

Participants felt that a lottery system was unfair owing to its basis in randomness rather than reason. They also felt that, with a lottery, one may never get chosen, whereas with a wait-list, one's turn would eventually be reached. First-come, 
Table 2: Themes and corresponding illustrative quotes

Theme/subtheme

Illustrative quote

\section{Procedural justice}

Transparency from clinics

I wasn't made aware of any sort of transparent process, I was just told I'm on a wait-list with no contact information or where I am on the wait-list. Is it a lottery wait-list? Is it a time-based wait-list? I have no idea, and I also didn't know it's the clinic [itself] that [is] doing it. (Focus group 3; participant 2)

At the least ... if the clinics are doing different things, I think they need to be extremely transparent about what they're doing, at least you're going in with your eyes open ... understanding the difference from clinic to clinic. ... That way you can make an informed decision. (Focus group 4; participant 2)

Consistency among clinics It just doesn't make sense. If I walk down the street and go to another clinic, I'm going to get ... different care. This is completely contrary to ... what the Ontario health care system, Canadian health care system is about. (Focus group 3; participant 1)

There has to be [the] same criteria. It kind of made me mad, to be honest, that now I have to shop around? To see which clinic I would have better options with? (Focus group 2; participant 1)

Gatekeeping of funding wait-list

I was on the list at [Hospital X] just because they threw me on first time I met with them. But at another place, they wouldn't; they said to wait. But I don't know if it's because they had a different system that wasn't first-come, first-served. (Focus group 4; participant 4)

They need to have some kind of standardized protocol. ... This person comes into [the] clinic ... first assessment, whole bunch of different tests, then we're going to try [intrauterine insemination] if that's an option. We do at least 3 or 4 [procedures]; if you don't get pregnant by 3 , then it's no chance versus ... somebody who comes into the clinic [for whom intrauterine insemination] is not an option, could be low sperm count or whatever it is, and then they go to IVF right away. But again transparency - needs to be a clear process, and if you don't get placed on the list right away you need to know why. (Focus group 3; participant 1)

I received the email by the end of last year, that ... "We have an opening," so I replied to the email right away, and then I didn't hear anything and I thought "I probably didn't make it," so next time when I saw the doctor to do the timed intercourse ... they told me "We have an opening, do you want to be on the list?" I said "Sure!" (Focus group 4; participant 3)

\section{Substantive and distributive justice}

Provide fair chance and equal access to IVF

Methods of distribution of funds by clinics
I think when you define success, to the ministry it's live births. I know that's the end goal, but success ... as a society... is the access. That is, giving everybody a chance. Even for me, if I had multiple cycles and it didn't work ... the end result wasn't live birth, but ... emotionally ... I would feel like I gave it all my all and I tried. And that would have [given] me peace of mind no matter the age. (Focus group 3; participant 2)

Age is another important factor ... the people who are closest [to age 43] should be able to get on this list as soon as possible so they have as many chances as they can to get [funding]. (Focus group 3; participant 1)

I actually have a kid, and I don't think ... I should have priority over someone who doesn't have a kid. (Focus group 3; participant 1)

\section{Barriers and challenges to accessing IVF}

Lack of information and communication

It's already, like, you're trying to remember how to take the medication and everything else; there's a huge list [of extra fees] and [you have to] strain out what's actually relevant to you, it's just a little overwhelming. (Focus group 4; participant 4)

I literally got a new phone because I need my phone to always be charged and available because that one day it's not available and I can't get a hold of them, and I miss a call, and they leave a message, and if I have a question about the message, [it's hard] getting a hold of them. (Focus group 4; participant 4)

Cost of fertility treatments Aside from the procedure, even just the medication is enough to ... even this month, me and my husband are very tight on our finances, this month we had to struggle more because we had to pay for the freezing of the embryos, the medication; [my husband] almost fell over and passed out seeing what we're paying for. (Focus group 4; participant 4)

Stress of experiencing infertility
It's an emotional time when you're going to a fertility clinic and you're being told what your options are and are not, and I feel like for me to be able to make a good decision, a right decision, there should be social worker involvement, or even a psychologist to put things into perspective would have been helpful. It almost feels like a factory at times, when you're just another patient. (Focus group 2; participant 1)

Note: IVF = in vitro fertilization 
first-served was seen by some as an acceptable method to distribute the funds, provided there is appropriate wait-list oversight.

A scoring system based on objective factors seemed to be the most appealing method to the participants because they felt there was more reasoning behind the allocation decisions. When deliberating on factors for scoring, they acknowledged the system's contention in practice. Most agreed that greater age should be the top factor prioritized since these women are "running out of time."

Age is another important factor ... the people who are closest [to age 43] should be able to get on this list as soon as possible so they have as many chances as they can to get [funding]. (Focus group 3; participant 1)

Another consistent factor discussed was previous children; even women with children agreed that this factor should put the person at a lower priority on the wait-list. Participants acknowledged that defining previous children can be challenging with blended families.

Participants discussed that the duration of infertility should be factored, as time spent waiting is stressful. However, one participant noted that this is subjective and should not be considered. Opinions on income varied from disregarding income to giving priority to those with greatest financial need. Other factors inconsistently mentioned were fitness to parent, medical dependence on IVF and medical urgency for IVF (e.g., a cancer treatment window).

Participants also discussed pitfalls of a scoring system and addressing people with equal priority. They suggested that those with equal scores should be entered on a first-come, first-served wait-list and that the scoring system should be reassessed every few months, with time spent waiting factored into the score. This would allow those with lower priority to eventually get their chance at a funded IVF cycle. Some participants proposed an online tool to self-assess priority. This would allow for increased transparency and personal planning, and ensure consistency.

\section{Barriers and challenges in accessing in vitro fertilization}

\section{Lack of information and communication}

Participants perceived a lack of communication and support with respect to managing their fertility medications and when they would receive IVF. They felt that receiving information in writing and a patient navigator would help facilitate the IVF process and their ability to comanage other aspects of their lives.

\section{Cost of fertility treatments}

Some participants reported that, to receive previous privately funded IVF cycles, they had had to take out loans, and others acknowledged that, without the OFP, assisted reproductive technology would not even be an option. Even with a funded cycle, financial barriers exist owing to the cost of medication (about $\$ 5000$ per IVF cycle) and storage and ancillary fees. ${ }^{4}$

\section{Stress of experiencing infertility}

Participants cited substantial emotional stress in dealing with infertility, which created additional challenges in navigating the OFP. Contributing factors were the length of time waiting and hearing about others who became pregnant easily. Appointment frequency and invasive examinations were tiring. Participants advocated for more psychosocial supports:

It's an emotional time when you're going to a fertility clinic and you're being told what your options are and are not, and I feel like for me to be able to make a good decision, a right decision, there should be social worker involvement, or even a psychologist to put things into perspective would have been helpful. (Focus group 2; participant 1)

\section{Interpretation}

This study provides patients' perspectives on a fair allocation system of publicly funded IVF. Important procedural elements included transparency and consistency among clinics regarding fund distribution and standardization of registration on wait-lists. Participants strongly advocated for equal access, regardless of outcomes. With respect to fund distribution, participants preferred a scoring system, with consideration of time spent waiting, so that relevant factors could be considered. Participants mentioned a lack of information, the financial burden and the stress of infertility as major challenges to accessing publicly funded IVF.

The findings show that, according to people who require assisted reproductive technology, success is defined as a chance to conceive. Without undergoing IVF, those with infertility may feel they have not tried all possible options, and this may leave them with feelings of regret. Thus, an approach that optimizes everyone's access to assisted reproductive technology was preferred over an approach that optimizes an outcome of increased live births.

Our qualitative findings confirm patient survey results showing that most patients believed there should be a standardized policy, a scoring system should be used, and access rather than outcome should be prioritized. ${ }^{7}$ In addition, they help clarify which factors should be considered within the scoring system. In New Zealand, Gillett and colleagues ${ }^{10}$ asked patients and health care practitioners to rank up to 10 factors that they deemed important for determining eligibility for funded IVF. ${ }^{10}$ The top 4 factors prioritized were duration of infertility, unlikelihood of conception without IVF, younger age of the woman and fewest living children. In our study, giving lower priority to those with living children was a common theme. Our participants discussed the duration of infertility and need for IVF but overall felt that these factors were too subjective. The participants in Gillett and colleagues' study ${ }^{10}$ felt that giving priority to younger women to optimize the number of live births was important, whereas our participants felt that giving priority to older women was important. Gillett and colleagues' study ${ }^{10}$ was done before New Zealand's publicly funded IVF system was developed, and thus it is possible that their participants were not aware an 
age cut-off would be imposed. This may explain why they did not feel that older women, who may age past the cut-off, should be given priority.

\section{Limitations}

Limitations of our study include a small sample and singleinstitution recruitment. There was a lack of diversity with regard to ethnicity, gender and relationship status. Participants had disproportionately higher incomes, and this may have affected their perspectives on how funds should be allocated, for example, whether financial need should be considered. Participants' perspectives may have been biased by the communication strategies used at this single fertility clinic, which may be different at other clinics across Ontario. The way the OFP was introduced during the focus groups and the researchers' roles may have influenced participants' responses. Potential participants who lived farther away were less likely to enrol in the study owing to distance and time requirements. As a result, all our participants were from Toronto or the Greater Toronto Area. Furthermore, since we selected patients at a fertility clinic, the population that has not attended a fertility clinic and the associated upfront barriers to accessing fertility treatment were missed. Last, our interpretations may have been biased by personal perspectives. C.J. and E.-J.S. work at the fertility clinic, and their bias is to advocate for the individual patient in front of them, sympathizing with her personal stories. A.A., N.C. and K.B. are outsiders to the fertility clinic with ethics training. Collectively, our biases shaped the topic guide and focus group guidance, and thus questions important to patients may have been missed. We attempted to minimize this bias by allowing participants to lead discussion and raise points that were not in the topic guide.

\section{Conclusion}

Currently, there are no standardized strategies among participating clinics to decide how publicly funded IVF should be distributed. Ensuring equal and fair access to funds should be prioritized. Information about the process and distribution method to obtain OFP funding should be clearly provided to patients. At the very least, transparency and communication should be prioritized to increase substantive rights for patients and reduce emotional stress. We hope the results of this study will be considered by relevant stakeholders, including the Ontario Ministry of Health and Long-Term Care, fertility clinic directors in Ontario and any other jurisdictions with a similar funding program.

\section{References}

1. Greenblatt E. Advisory process for infertility services key recommendations report. Toronto: Ministry of Health and Long-Term Care; 2015. Available: http:// health.gov.on.ca/en/public/programs/ivf/docs/ivf_report.pdf (accessed 2018 Sept. 19).

2. Ontario announces 50 clinics offering government-funded fertility treatments [news release]. Toronto: Ministry of Health and Long-Term Care; 2015 Dec. 11. Available: https://news.ontario.ca/mohltc/en/2015/12/ontario-announces -50-clinics-offering-government-funded-fertility-treatments.html (accessed 2019 Apr. 14)

3. Blackwell T. Waitlists for IVF stretch to 2018. National Post [Toronto] 2016 May 26. Available: https://www.pressreader.com/canada/national-post-latest -edition/20160526/281505045461992 (accessed 2019 Apr. 14).

4. Get fertility treatments. Ontario.ca. Toronto: Ministry of Health and LongTerm Care; updated 2019 Apr. 9. Available: https://www.ontario.ca/page/get -fertility-treatments (accessed 2019 Apr. 12)

5. Participating clinics in the fertility program. Toronto: Ministry of Health and Long-Term Care; modified 2019 Apr. 4. Available: http://health.gov.on.ca/ en/public/programs/ivf/pub_clinics.aspx (accessed 2019 Apr. 14).

6. Gotz T, Jones C. Prioritization of patients for publicly funded IVF in Ontario: a survey of fertility centres. 7 Obstet Gynaecol Can 2017;39:138-44.

7. Gotz T, Goldstein S, Chauhan N, et al. Distribution of funded IVF in Ontario: a patient perspective. Presented at the Canadian Fertility and Andrology Society conference; 2017 Sept. 14-16; Vancouver, BC.

8. Corbin J, Strauss A. Basics of qualitative research: techniques and procedures for developing grounded theory. 3rd ed. Thousand Oaks (CA): SAGE Publications; 2008:1-18.

9. Creswell JW. Qualitative inquiry and research design: choosing among five approaches. Thousand Oaks (CA): SAGE Publications; 2013.

10. Gillett WR, Peek JC, Herbison GP. Development of clinical priority access criteria for assisted reproduction and its evaluation on 1386 infertile couples in New Zealand. Hum Reprod 2012;27:131-41.

11. Canadian Assisted Reproductive Technologies Registry (CARTR) Plus. Final treatment cycle and pregnancy outcome data for 2015. Ottawa: Better Outcomes Registry \& Network Ontario; 2018.

Affiliations: Sunnybrook Health Sciences Centre (Assal); Joint Centre for Bioethics (Assal, Chauhan), University of Toronto; Department of Bioethics (Chauhan, Bowman) and Mount Sinai Fertility (Shin, Jones), Mount Sinai Hospital, Sinai Health System; Departments of Family and Community Medicine (Bowman) and Obstetrics and Gynaecology (Jones), Faculty of Medicine, University of Toronto; Faculty of Medicine (Assal), University of Toronto, Toronto, Ont.

Contributors: Angela Assal and Nipa Chauhan acquired and analyzed the data. Angela Assal drafted the manuscript. All of the authors contributed to the study conception and design, and data interpretation, critically revised the manuscript for important intellectual content, approved the version to be published and agreed to be accountable for all aspects of the work.

Funding: This study was supported by a research grant from the Department of Obstetrics and Gynaecology, Mount Sinai Hospital, Sinai Health System. Eyun-Jung Shin is supported by the University of Toronto Gynecologic Reproductive Endocrinology \& Infertility Fellowship Fund, which is sponsored by unrestricted research grants from EMD Serono, Merck Canada and Ferring Pharmaceuticals.

Acknowledgements: The authors thank the Department of Obstetrics and Gynaecology at Mount Sinai Hospital, Sinai Health System for providing a research grant to support this study. They also thank the patients who took the time to participate in this study.

Supplemental information: For reviewer comments and the original submission of this manuscript, please see www.cmajopen.ca/content/7/2/ E385/suppl/DC1. 